\title{
DESEMPENHO DE FRANGOS DE CORTE, SEXADOS, SUBMETIDOS A DIETAS FORMULADAS PELOS CONCEITOS DE PROTEÍNA BRUTA versus PROTEÍNA IDEAL ${ }^{1}$
}

\author{
PERFORMANCE OF SEXED BROILER BIRDS, SUBMITTED \\ TO DIETS FORMULATED BY THE CONCEPTS OF \\ CRUDE PROTEIN versus IDEAL PROTEIN ${ }^{1}$
}

\author{
Maria Olinda Bergamo Mendoza ${ }^{2}$ Paulo Tabajara Chaves Costa ${ }^{3}$ Lia Helena Katzer ${ }^{4}$ \\ Antonio Carlos Benetti ${ }^{5}$ Zenita Bisognin Santi ${ }^{5}$ José Nelson Welter $^{5}$
}

\section{RESUMO}

O trabalho foi conduzido no Setor de Avicultura do Departamento de Zootecnia da Universidade Federal de Santa Maria com o objetivo de verificar as respostas de desempenho de frangos de corte, criados com sexos separados, alimentados pelo conceito tradicional (Proteína Bruta - PB) em comparação a dietas formuladas pelo critério de Proteína Ideal (PI), num período de 1 a 42 dias de idade. A análise econômica comparativa entre os dois métodos de alimentação também foi realizada. Foram utilizados 960 pintos de corte de um dia de idade $(480$ machos, 480 fêmeas) da linhagem ROSS. As dietas experimentais baseadas no conceito de PB foram formuladas segundo as recomendações do NRC (1994) e as dietas formuladas pelo conceito de PI foram adaptadas de HAN \& BAKER (1994). O delineamento experimental foi o inteiramente casualizado, constituindo 4 tratamentos com 12 repetições de 20 aves cada. Foram estudados os parâmetros: consumo alimentar, ganho de peso e peso corporal, ganho médio diário, conversão alimentar e índice de eficiência nutricional. Os resultados obtidos indicaram que os parâmetros estudados foram mais influenciados na fase inicial. As dietas formuladas pelo conceito de PI, baseada no conteúdo de aminoácidos digestíveis (AAD), influenciaram positivamente os parâmetros estudados, proporcionando significativos melhores ganhos de peso e eficiência alimentar, tanto para os machos quanto para as fêmeas nas fases inicial e total, sendo similares nas demais fases. As aves alimentadas com AAD apresentaram uma maior lucratividade nas fases inicial e crescimento. Esses dados permitem concluir que dietas à base de milho e farelo de soja, formuladas para atender às exigências de $A A D$, proporcionam melhores desempenhos biológico e econômico, em relação àquelas formu- ladas à base de $\mathrm{PB}$, do primeiro até os 35 dias de idade. A fase final mostrou o contrário, sendo o conceito de PB mais econômico do que a $\mathrm{Pl}$.

Palavras-chaves: frangos de corte, desempenho, proteína bruta, proteína ideal.

\section{SUMMARY}

The study was carried out at the Poultry Section of the Departament of Animal Science at Federal University of Santa Maria, in order to evaluate the performance of broilers grown sexed and fed with diets formulated by the traditional concept (Crude Protein - CP), which is based on total amimo acids (TAA) and fed with the approach of Ideal Protein (IP), which is based on digestible amino acids (DAA), in the period from 1 to 42 days of age. A comparative economic analysis among the two feeding methods was also accomplished. There were 960 chicks (Ross) at the age of 1 day, being 480 males and 480 females. The diet based on the concept of CP was formulated according to the recommendation of NRC (1994) and the diet formulated by the concept of IP was adapted from Han and Baker (1994). The completely randomized experimental design consisted of 4 treatments with 12 replications of 20 chicks each. The feed intake, phase gain, body weight, daily gain, feed conversion and the nutritional efficieny index were evaluated. The results indicated that the parameters studied were more efficient in the initial phase. The diet formulated by the Ideal Protein concept, based on the content of DAA, influenced all parameters studied positively, providing significantly better gain weight and feed efficiency in both male and female chicks in the initial and final

\footnotetext{
${ }^{1}$ Parte da dissertação de Mestrado apresentada pelo primeiro autor ao Curso de Pós-graduação em Zootecnia, Universidade Federal de Santa Maria (UFSM)

${ }^{2}$ Zootecnista, Mestre em Zootecnia, Rua Erly de Almeida Lima, 67, Camobi, 97105-120, Santa Maria-RS. Autor para correspondência.

${ }^{3}$ Médico Veterinário - Pesquisador CNPq.

${ }^{4}$ Acadêmica de Veterinária, UFSM.

${ }^{5}$ Acadêmicos de Zootecnia, UFSM
} 
phases, being similar in the growing phase. The chicks fed with DAA showed greater profits in the initial phase and during the growth phase. These data allowed the conclusion that diets containing corn and soybean meal as base for the formulated feed provides better biological and economic performance of the broilers when compared to those formulated with crude Protein, from day the first up to 35 days of age. The final phase (35-42) showed the contrary, being the CP concept more economical than IP.

Key words: broilers, performance, crude protein, ideal protein.

\section{INTRODUÇÃO}

Desde o início deste século, as rações para aves eram formuladas para satisfazer as necessidades de proteína bruta (PB) dos animais. Com a crescente entrada dos aminoácidos (AA) sintéticos no mercado (década de 1950), os nutricionistas puderam passar a formular as dietas com o objetivo de satisfazer as necessidades específicas de aminoácidos essenciais (AAE).

Nos últimos 20 anos, muitas foram as pesquisas para determinar as exigências dos $\mathrm{AAE}$ para frangos de corte, sendo impossível, entretanto, segundo alguns pesquisadores, estabelecer as exigências de cada AAE para cada situação encontrada a campo, devido ao grande número de fatores ambientais, sanitários, nutricionais, genéticos e até mesmo mercadológicos que interagem e interferem na determinação do nível ótimo para cada AAE da ração. O conceito de proteína ideal surgiu como solução, em que a exigência de um dado $\mathrm{AAE}$, como AA digestível (AAD), passa a ser fornecida à ave desde que as proporções ótimas entre todos os AAE sejam respeitadas no momento da formulação. Segundo PARSONS \& BAKER (1994), para ser ideal, a proteína ou a combinação protéica não deve possuir aminoácidos em excesso. Isso representa uma fonte dispendiosa de energia metabolizável (EM ) e representa um prejuízo ao meio ambiente por causa da poluição pelo nitrogênio excretado.

De acordo com BAKER \& HAN (1994), em situações práticas, os aminoácidos sulfurados (AAS), Lisina (LIS), treonina (TRE), triptofano (TRP), valina (VAL) e arginina (ARG) são os AAE de maior importância para a produção de aves e suínos. A proposta na nutrição animal é que cada AAE seja expresso, em relação à percentagem, a um AA referência, possibilitando estimar rapidamente a exigência de todos os $\mathrm{AAE}$ quando a exigência do AA referência estiver estabelecida. Essa proposta permite manter uma proporcionalidade entre todos os AA da dieta.

Segundo ROSA et al. (1995), a composição em AAD de uma ração formulada à base de milho e farelo de soja, de acordo com as exigências de AA total e PB recomendados pelo NRC (1994) é bastante diferente da proporção dos AAD proposta por PARSONS \& BAKER (1994). Baseados nisso, os autores comparam o desempenho e a economicidade de frangos de corte com as recomendações para AA total (AAT) e PB, recomendadas pelo NRC (1994) ou segundo as recomendações de AAD de PARSONS \& BAKER (1994), não encontrando diferenças no ganho de peso e consumo de ração e na avaliação da eficiência econômica.

Conforme ROSTAGNO et al. (1995), a formulação com base em AAD promove um desempenho mais consistente, principalmente quando são usados ingredientes diferentes do milho e do farelo de soja. Esses autores, ao avaliarem diferentes rações para frangos de corte, contendo os mesmos níveis de LIS e AAS digestíveis, com o objetivo de verificar se proporcionariam desempenho semelhante às aves, perceberam que rações formuladas com baixos níveis de AAD proporcionaram pior ganho de peso e conversão alimentar em relação à ração contendo altos níveis de AAD. Quando as aves receberam uma ração contendo ingredientes com baixa digestibilidade de AA, mas suplementadas com AA sintéticos, a queda no desempenho foi evitada. De acordo com ALBINO \& SILVA (1996), o conhecimento da digestibilidade dos AA nos alimentos é particularmente importante na formulação de rações, uma vez que permite a utilização de uma grande gama de alimentos, entre eles os subprodutos industriais e os alimentos alternativos. Segundo os mesmos autores, dentre as várias características avaliadas, durante a determinação de exigências nutricionais para frangos de corte, o ganho de peso é considerado como característica base, principalmente em animais jovens e com rápida velocidade de crescimento. Porém, poucos estudos têm sido conduzidos visando estabelecer as exigências nutricionais para frangos de corte criados com separação de sexo, não apenas em AA, mas também em minerais e vitaminas que respondem por uma fração importante dos custos e nas respostas produtivas.

Baseados nessas informações, conduziuse este experimento com a finalidade de verificar o desempenho de frangos de cortes, criados com sexo separado, comparando dois tipos de alimentação: uma ração formulada com base nos AAT (PB) e outra ração baseada na formulação em AAD (PI).

\section{MATERIAL E MÉTODOS}

$\mathrm{O}$ experimento foi conduzido no setor de Avicultura do Departamento de Zootecnia da Universidade Federal de Santa Maria - UFSM, em 
Santa Maria, localizada na Depressão Central do Estado do Rio Grande do Sul, com latitude $30^{\circ} \mathrm{S}$ e altitude $150 \mathrm{~m}$, tendo temperatura e umidade relativa ao ar, médias anuais, $19^{\circ} \mathrm{C}$ e $82 \%$, respectivamente. Utilizaram-se 960 pintos tipo corte, sexados (480 machos, 480 fêmeas) de um dia de idade, da linhagem comercial Ross, oriundos da Frangosul de Montenegro, RS, alojados em um galpão experimental para frangos de corte de $10 \mathrm{~m}$ de largura e $27 \mathrm{~m}$ de comprimento, com orientação Leste-Oeste, dividido em 52 boxes telados de $1,5 \times 1,5 \mathrm{~m}$, dos quais 48 foram preparados com cama de maravalha $(10 \mathrm{~cm})$, uma campânula elétrica com lâmpada incandescente de 100 Watts, um bebedouro pendular automático e um comedouro tipo bandeja que foi substituído no $7^{\mathrm{o}}$ dia por um comedouro tubular $(15 \mathrm{~kg})$ e utilizados para o alojamento. Por ocasião deste, as aves foram pesadas e distribuídas ao acaso, em grupos de 20 aves por parcela, de acordo com os tratamentos, que já haviam sido previamente distribuídos de forma sistemática e balanceada nas unidades experimentais de acordo com a posição geográfica de cada repetição dentro da instalação, de modo que um número idêntico de repetição de cada tratamento estivesse representado em cada linha de parcelas, seguindo o exemplo realizado for MARIANI (1998). A partir do alojamento, as aves tiveram livre acesso à água e às dietas experimentais. Os bebedouros foram lavados diariamente e os comedouros observados quanto ao conteúdo de ração, sendo abastecidos sempre que necessário.

O período experimental constou de 3 fases: Inicial (1-20 dias), Crescimento (21-35 dias) e Final (36-42 dias), para as quais foram formuladas 4 dietas por fase, totalizando 12 dietas experimentais. As dietas experimentais (Tabela 1) a base de milho e farelo de soja foram formuladas respeitando-se os requerimentos nutricionais por sexo e por fase. Nas dietas experimentais formuladas pelo conceito de
$\mathrm{PB}$, considerou-se um diferencial de $7,5 \%$ entre machos e fêmeas dentro de uma mesma fase e, igualmente $7,5 \%$ decrescente entre as fases em relação ao nível protéico, baseados nos requerimentos do NRC (1994). As dietas experimentais baseadas no conceito de PI foram formuladas a partir dos requerimentos em AAD propostos por HAN \& BAKER (1994). A concentração dos AAD presentes nos ingredientes utilizados foi obtida a partir de cálculos de regressão, baseados em 257 amostras de milho e 547 de farelo de soja, publicados por BAKER (1995). Nessas dietas, foram utilizados os AAE sintéticos, L-Lisina e DL-metionina a fim de suprir as exigências de AAE.

$\mathrm{O}$ delineamento experimental foi inteiramente casualizado, constituindo 4 tratamentos, com 12 repetições de 20 aves cada, sendo: $\mathrm{T}_{1}$ (macho, conceito $\mathrm{PB}$ ); $\mathrm{T}_{2}$ (fêmea, conceito $\mathrm{PB}$ ); $\mathrm{T}_{3}$ (macho, conceito PI) e $\mathrm{T}_{4}$ (fêmea, conceito PI). Os parâmetros avaliados foram o peso corporal $(\mathrm{g})$, o consumo de ração $(\mathrm{g})$, a conversão alimentar, o ganho médio diário (g) e o índice de eficiência nutricional. Também foi realizada uma análise bio-econômica. Para o parâmetro peso corporal, as aves foram pesadas individualmente em balança com aproximação de $10 \mathrm{~g}$ ao final de cada fase. As sobras de ração, fornecidas "ad libitum", eram coletadas e pesadas com a finalidade de determinar o consumo, no mesmo dia da pesagem das aves. A conversão alimentar das aves foi expressa em $\mathrm{kg}$ de ração consumida por $\mathrm{kg}$ de peso produzido. O ganho médio diário foi calculado através do peso da ave dividido pelo número de dias experimentais. Para determinar o índice de eficiência nutricional, levaram-se em conta as variáveis ganho médio diário e conversão alimentar.

Dentro da análise bio-econômica foram calculados os custos das dietas experimentais, considerando o preço em reais dos ingredientes utilizados no experimento, bem como o índice de eficiência bio-econômica utilizado para calcular a quantidade

Tabela 1 - Valores nutricionais das dietas experimentais segundo as respectivas fases: inicial (I), crescimento (C) e final (F) para machos (M) e fêmeas $(F)$.

\begin{tabular}{|c|c|c|c|c|c|c|c|c|c|c|c|c|}
\hline & \multicolumn{6}{|c|}{ PB } & \multicolumn{6}{|c|}{ PI } \\
\hline & \multicolumn{2}{|c|}{ I } & \multicolumn{2}{|c|}{$\mathrm{C}$} & \multicolumn{2}{|c|}{$\mathrm{F}$} & \multicolumn{2}{|c|}{ I } & \multicolumn{2}{|c|}{$\mathrm{C}$} & \multicolumn{2}{|c|}{$\mathrm{F}$} \\
\hline EM & \multicolumn{2}{|c|}{3050} & \multicolumn{2}{|c|}{3150} & \multicolumn{2}{|c|}{3250} & \multicolumn{2}{|c|}{3050} & \multicolumn{2}{|c|}{3150} & \multicolumn{2}{|c|}{3250} \\
\hline $\mathrm{Ca}$ & \multicolumn{2}{|c|}{0,90} & \multicolumn{2}{|c|}{0,90} & \multicolumn{2}{|c|}{0,80} & \multicolumn{2}{|c|}{0,90} & \multicolumn{2}{|c|}{0,90} & \multicolumn{2}{|c|}{0,80} \\
\hline \multirow[t]{2}{*}{$\mathrm{P}$} & \multicolumn{2}{|c|}{0,45} & \multicolumn{2}{|c|}{0,45} & \multicolumn{2}{|c|}{0,40} & \multicolumn{2}{|c|}{0,45} & \multicolumn{2}{|c|}{0,45} & \multicolumn{2}{|c|}{0,40} \\
\hline & M & $\mathrm{F}$ & M & $\mathrm{F}$ & M & $\mathrm{F}$ & M & $\mathrm{F}$ & M & $\mathrm{F}$ & M & $\mathrm{F}$ \\
\hline $\mathrm{PB} \%$ & 22,0 & 21,27 & 21,27 & 19,27 & 19,67 & 18,19 & 22,43 & 20,57 & 18,74 & 17,85 & 15,68 & 15,74 \\
\hline LIS Bruta (b) & 1,27 & 1,15 & 1,115 & 1,04 & 1,05 & 0,94 & - & - & - & - & - & - \\
\hline LIS Digestível (d) & - & - & - & - & - & - & 1,12 & 1,02 & 0,89 & 0,84 & 0,70 & 0,69 \\
\hline $\mathrm{MET}+\mathrm{CIS}$ b & 0,72 & 0,68 & 0,68 & 0,64 & 0,63 & 0,60 & - & - & - & - & - & - \\
\hline MET + CIS d & - & - & - & - & - & - & 0,80 & 0,73 & 0,64 & 0,64 & 0,50 & 0,49 \\
\hline
\end{tabular}

Ciência Rural, v. 31, n. 1, 2001. 
de recursos dispendidos em alimentação para produzir uma tonelada de peso vivo. O mesmo foi obtido através da fórmula: $(A / B-C \rightarrow D / C=E)$, onde $A=$ ganho de peso, $\mathrm{B}=$ consumo alimentar, $\mathrm{C}=$ eficiência alimentar, $\mathrm{D}=$ custo da ração $(\mathrm{R} \$), \mathrm{E}=$ custo Ton/Ganho (R\$). A eficiência alimentar foi calculada dividindo-se o ganho de peso pelo consumo alimentar no período experimental. O cálculo do custo do ganho (R $\$ / T o n)$ foi obtido dividindo-se o custo da ração pela eficiência alimentar.

As análises estatísticas foram realizadas através do programa SAS, versão 6.08 (Statistical Analysis System, 1989). Os dados obtidos foram submetidos à análise de variância e nos parâmetros que acusaram diferenças estatísticas significativas a $5 \%$, as médias foram comparadas pelo teste de Tukey.

\section{RESULTADOS E DISCUSSÃO}

Os dados de consumo de ração $(\mathrm{CR})$, peso corporal (g), conversão alimentar (CA), ganho médio diário $(\mathrm{GMD} / \mathrm{g})$ e índice de eficiência nutricional (IEN) encontram-se na tabela 2. Para o parâmetro alimentar, verificou-se que as rações $\mathrm{T}_{3}$ e $\mathrm{T}_{4}$ suplementadas com AA sintéticos para fornecer as exigências em AAD melhoraram o consumo de ração das aves em relação ao fornecimento das rações $\mathrm{T}_{1} \mathrm{e}$ $\mathrm{T}_{2}$ que forneceram as exigências de AAT. Esses resultados concordam com os de DARI (1996), que observou um aumento no consumo de ração ao alimentar frangos de corte (21-42 dias), com dietas formuladas com base em AAD, e com os de ROSA et al. (1995) que obtiveram um consumo de ração de 4086g para aves alimentadas com a recomendação de AAD de PARSONS \& BAKER (1994), quando comparada com a composição da dieta recomendada para PB pelo NRC (1994) que consumiram 3971g.

Tabela 2 - Efeito do conceito de Proteína e do sexo sobre o consumo de Ração (CR)g, peso corporal (PC)g, conversão alimentar (CA), ganho médio diário (GMD) e índice de eficiência nutricional (IEN) no período experimental (1-42 dias).

\begin{tabular}{clllll}
\hline Tratamento & CR & PC & CA & GMD & IEN \\
\hline 1 & $4411^{\mathrm{b}}$ & $2385^{\mathrm{b}}$ & $1,85^{\mathrm{a}}$ & $56,80^{\mathrm{b}}$ & $305^{\mathrm{b}}$ \\
2 & $4000^{\mathrm{d}}$ & $2044^{\mathrm{d}}$ & $1,96^{\mathrm{b}}$ & $48,67^{\mathrm{d}}$ & $249^{\mathrm{d}}$ \\
3 & $4755^{\mathrm{a}}$ & $2553^{\mathrm{a}}$ & $1,86^{\mathrm{a}}$ & $60,79^{\mathrm{a}}$ & $326^{\mathrm{a}}$ \\
4 & $4^{\mathrm{c}}$ & $2142^{\mathrm{c}}$ & $1,94^{\mathrm{b}}$ & $51,0^{\mathrm{c}}$ & $263^{\mathrm{c}}$ \\
Média & & 2281 & 1,90 & 54,31 & 286 \\
C V (\%) & & 3,14 & 1,75 & 3,14 & 4,0 \\
\hline
\end{tabular}

Médias seguidas por letras diferentes, nas colunas, diferem entre si pelo teste de Tukey a $5 \%$.
O peso corporal acumulado aos 42 dias evidenciou diferenças significativas $(\mathrm{P}<0,05)$ entre todos os tratamentos, sendo que as aves (machos e fêmeas) alimentadas com as dietas formuladas pelo conceito de PI apresentaram peso corporal mais elevado quando comparadas com as demais. Nesses parâmetros, os machos do conceito de PI obtiveram um peso corporal superior em relação aos machos do conceito de PB, apresentando um GMD de 60,79g contra um GMD de $56,80 \mathrm{~g}$, respectivamente. As fêmeas, nesse período, apresentaram diferenças significativas entre si, pois aquelas alimentadas com dietas formuladas com o conceito de PI obtiveram um peso de $2142 \mathrm{~g}$ e GMD de $510 \mathrm{~g}$ comparadas com as fêmeas do conceito de PB que apresentaram um peso de $2044 \mathrm{~g}$ e GMD de 48,67g. Em relação ao sexo, os machos apresentaram um ganho de peso $17,9 \%$ superior em relação às fêmeas.

Esses resultados indicam que a formulação de dietas baseadas nas exigências de AAD oferece aporte adequado de AA para que a ave maximize o seu desempenho, concordando com HUYGHEBAERT \& PACK (1994) que reforçam a importância do equilíbrio correto de AA para um ótimo desempenho e máxima utilização das proteínas da dieta.

Analisando os dados de conversão alimentar, não houve diferenças significativas ( $\mathrm{P}$ > $0,05)$ entre os conceitos utilizados, quando comparadas dentro do mesmo sexo, sendo os índices de conversão alimentar similares entre os machos e entre as fêmeas. Quando comparados os sexos, os machos foram mais eficientes em conversão, apresentando os índices de 1,85 e 1,86 para machos PB e PI respectivamente, em relação às fêmeas que obtiveram índices de conversão alimentar de 1,96 e 1,94 para fêmeas PB e PI, respectivamente. $\mathrm{O}$ índice de conversão alimentar médio dos tratamentos obtidos neste estudo foi de 1,90, indicando que as aves foram eficientes para este parâmetro quando criadas até os 42 dias de idade. Avaliando-se essas duas variáveis, $\mathrm{PC}$ e CA, verifica-se que com idêntico $\mathrm{CA}$ obtiveram-se, também, mais de $6 \%$ de ganho corporal favorável ao conceito de PI.

A análise do IEN evidenciou diferenças significativas $(\mathrm{p}<0,05)$ entre todos os tratamentos, sendo que os machos alimentados dentro do conceito de PI foram superiores quanto à eficiência nutricional, sendo 5,8\% mais eficientes. Entre as fêmeas, o melhor IEN obtido foi para aquelas aves alimentadas mediante o conceito de PI, que apresentaram um diferencial de 5,6\% superior em relação às fêmeas que compunham o outro tratamento. Quando comparados os sexos, os machos apresentaram uma melhor eficiência de utilização dos nutrientes em relação às fêmeas. 
Os dados dos custos das dietas experimentais $(\mathrm{R} \$ / \mathrm{Ton})$ e custo do ganho ( $\mathrm{R} \$ / \mathrm{T}$ on) encontramse na tabela 3. Ao analisar-se o período total do experimento, verifica-se que, apesar do custo do consumo de ração ser maior, a PI, ao proporcionar maior peso corporal, apresentou um menor custo do ganho, sendo $3,5 \%$ melhor, similar a resultados encontrados por ALBINO (1991), o qual observou que reações formuladas com base nos teores de AAD proporcionaram maior lucro parcial.

Tabela 3 - Custos das dietas experimentais ( $\mathrm{R} \$ /$ ton) e custo do ganho (R\$/ton), dispendidos no período de 1-42 dias.

\begin{tabular}{ccc}
\hline Tratamento & Custo dieta (R\$/ton) & Custo ganho (R\$/ton) \\
\hline 1 & 691,0 & $1.279,0$ \\
2 & 665,0 & $1.301,0$ \\
3 & 669,0 & $1.248,0$ \\
4 & 652,0 & $1.268,0$ \\
\hline
\end{tabular}

\section{CONCLUSÕES}

A formulação pelo conceito de PI promove uma diferença em ganho de peso $7 \%$ superior entre os machos e 4,8\% entre as fêmeas. A formulação de rações específicas para cada sexo é mais econômica e permite a obtenção de melhores resultados. Dietas à base de milho e farelo de soja, formuladas para atender às exigências de $\mathrm{AAD}$, proporcionam melhores desempenhos biológico e econômico, em relação àquelas formuladas à base de PB.

\section{REFERÊNCIAS BIBLIOGRÁFICAS}

ALBINO, L.F.T. Sistemas de avaliação nutricional de alimentos e suas aplicações, na formulação de rações para frangos de corte. Viçosa,1991. 141p. Tese (Doutorado).Universidade Federal de Viçosa, 1991.

ALBINO, L.F.T., SILVA, M.A. Tópicos avançados em exigências nutricionais para frangos de corte. In: CONGRESSO NACIONAL DE ZOOTECNIA, 1996, Porto Alegre. Anais... Porto Alegre, RS : SBZ, 1996. p.59-65.
BAKER, D.H., HAN, Y. Ideal aminoacid profile for chicks during the first weeks porthatching. Poult Sci, Champaign, v.73, p.1441-1447, 1994.

BAKER, D.H. Ideal protein for broiler chicks. Multi-state poultry meeting. n.i, p.13, 1995.

DARI, L.R. Uso de aminoácidos digestíveis e do conceito de proteína ideal na formulação de rações para frangos de corte. Porto Alegre, RS, 1996. 146p. Dissertação (Mestrados em Zootecnia) - Curso de Pós-graduação em Zootecnia, Universidade Federal do Rio Grande do Sul, 1996.

HAN, Y., BAKER, D.H. Digestive Lisine requeriment of male and female broiler chicks during the period three to six weeks posthatching. Poult Sci, Champaign, v.73, p.1739-1745. 1994.

HUYGHEBAERT, G., PACK, M. Effects of dietary protein content and addition of nonossential aminoacids on the response of broiler chicks to dietary sufur aminoacids. Europan Poultry Conference, Glosgow, v.1, p.465-466, 1994.

MARIANI, G.V.C. Desempenho produtivo de frangos de corte submetidos à intoxicação experimental com aflotoxina em diferentes idades. Santa Maria-RS, 1998. 79p. Dissertação (Mestrado em Zootecnia) - Curso de Pós-graduação em Zootecnia, Universidade Federal de Santa Maria. 1998.

NATIONAL RESEARCH COUNCIL(NRC). Nutrient requeriments of poultry. 9 ed. Washington, EUA: National Academy, 1994. 115p.

PARSONS, C.M., BAKER, D.H. The concept and usage of ideal proteins in the feeding of nonruminants. In: SIMPÓSIO INTERNACIONAL DE PRODUÇÃO DE NÃO RUMINANTES, 1994, Maringá. Anais... Maringá: EDUEM, 1994. p.119-128.

ROSA, P.S., BRUM, P.A.R., GUIDONI, A. Comparação de dietas práticas para frangos formuladas para atender diferentes exigências de aminoácidos. In: CONFERÊNCIA APINCO 1995 DE CIÊNCIA E TECNOLOGIA AVÍCOLAS 1995, Curitiba. Trabalhos de Pesquisa... Campinas: FACTA, 1995. p.63-64.

ROSTAGNO, H.S., PUPA, J.M.R., PACK, M. Diet formulation for broilers based on total versus digestible aminoacids. J Appl Poult Res, Athens, v.4, p.1-7, 1995.

SAS. INSTITUTE INC. SAS / STAT. Guide for personal computers: version G. 4 ed. Cary, NC, 1989. 1686p.

Ciência Rural, v. 31, n. 1, 2001. 